BOOK REVIEW:

"FRANK RAMSEY: A SHEER EXCESS OF POWERS"

BY CHERYL MISAK

REVIEWED BY

MARION GASPARD*

* University of Lyon 2, UFR Sciences Économiques et de Gestion.

Contact: marion.gaspard@univ-lyon2.fr

This "preprint" is the accepted typescript of a book review that is forthcoming in revised form, after minor editorial changes, in the Journal of the History of Economic Thought (ISSN: 1053-8372), issue TBA. Copyright to the journal's articles is held by the History of Economics Society (HES), whose exclusive licensee and publisher for the journal is Cambridge University Press (https://www.cambridge.org/core/journals/journal-of-the-history-of-economic-thought). This preprint may be used only for private research and study and is not to be distributed further.

The preprint may be cited as follows:

Gaspard, Marion. Review of "Frank Ramsey: A Sheer Excess of Powers" by Cheryl Misak. Journal of the History of Economic Thought (forthcoming). Preprint at SocArXiv, osf.io/preprints/socarxiv 
Cheryl Misak, 2020, Frank Ramsey: A Sheer Excess of Powers, Oxford University Press, (2020). ISBN 10 : 019875535X ISBN 13 : 9780198755357

\section{Marion Gaspard}

The 500-page biography Cheryl Misak devotes to Frank P. Ramsey (1903-1930) is an impressive and very dense book. It draws on thousands of archives, testimonies and pages of literature to reconstruct, step by step, Ramsey in context. Ramsey, the shooting star of analytical philosophy, mathematics and economics, is here a very human hero - a mind, a heart and a body - of a documentary look at every aspect at his environment. The context covers family backgrounds, friendships, relationships, as well as his institutional and intellectual environment, all of which converge in and around Cambridge in 1920. Misak manages to balance it all: the man and his world; the private person (Frank, the high-potential child gradually forging his own path) and the public person (Ramsey, the genius behind decisive contributions in history of ideas); the contextualization and the exposition of Ramsey's works.

The book is commensurate to Misak's ambition: "to make sense of all of Ramsey's work" (p. ix). A challenge she tackled with her in-depth knowledge of analytic philosophy, and of Cambridge pragmatism in particular", and with a strong sense of "setting the scene". Starting from a social view of Ramsey's death (the feeling of immense loss expressed by academics and intellectuals of the time), Misak returns to the roots (the ancestors) then spins the thread of Ramsey's life, month by month, alternating between chapters devoted to Frank, and others devoted to Ramsey. Ramsey's lectures, articles and drafts are placed in the precise and multidimensional context of their writing. The content of these writings is recalled by Misak herself and by prestigious guests - contemporary specialists in mathematics, economics and philosophy - in thematic text boxes. These scattered guest boxes are present testimonials of the lasting influence of the man we continue to discover in the main text. The book ends with a more intimate version of Frank Ramsey's death, when his thinking begins to become fully structured, in the writing of an unfinished book.

Misak knits and interweaves tremendous archival materials to feed her narrative. In addition to archives stored at the University of Pittsburgh, Misak draws on the private archives of Ramsey's wife, Lettice C. Baker, and of Ramsey's heirs, kept at King's College, Cambridge. This includes family letters, an autobiography of Ramsey's father, and diaries partially encountered in Margaret Paul's biography (2012), but which are more clearly referenced here. Misak supplements this material with a systematic use of archives that help describe and understand Ramsey's family, as well as Ramsey's environment at each stage of his life: Winchester College, Trinity college and Kings College archives when following Ramsey's years at school and university; Vienna Circle archives, Bertrand Russell, John Maynard Keynes, Ludwig Wittgenstein Collections, and so on. Misak also uses a series of interviews conducted in the early 1980s by Laurie Kahn. ${ }^{2}$ Misak's systematic and meticulous work on this abundant material is a subtle way of intersecting sources. It also creates a powerful effect of reality. Reading the chapters more specifically devoted to "Frank", we see Ramsey's childhood home,

\footnotetext{
${ }^{1}$ See Misak (2016), among numerous other contributions.

${ }^{2}$ Laura Lewiit Kahn planned at this time to write a biography of Ramsey as a thesis. (p. xxxiv).
} 
his dorms at Winchester or Trinity, the places he lived, all the way up to the ward of the hospital where he died. We hear the parental arguments, the conversations in the lounges of Bloomsbury, Wittgenstein's terrible outbursts of anger, and Ramsey's laughter. Misak's language is on par with that of the 1920s and blends into the decor.

Misak's achievement is not just one of setting the scene. Indeed, she is as concerned with portraying the players who comprise this documentary biography as with presenting the institutions in which they live and work. These two dimensions help shed light on Ramsey's singular trajectory with greater precision than existing biographies.

Research on Ramsey's works has seen a resurgence since the early 1990s, partially thanks to the publication of a new anthology of Ramsey's papers by Mellor (Ramsey 1990) ${ }^{3}$ and thanks to the transcription and selection of several manuscripts by Galavotti (Ramsey 1991a) and Rescher and Majer (Ramsey 1991b). It has been accompanied by a need to situate this brilliant young author in introductions to his contributions (Sahlin 1990; Mellor 1995; Dokic and Engel (2002); Bollobas and Thomason 2003; Taylor 2006; Duarte 2009). These essays often share a common narrative: A boy from a good family, son of a mathematician and Dean of Magdalene College Cambridge (Arthur S. Ramsey) and of a feminist intellectual (Agnes Wilson), younger brother of a future Archbishop of Canterbury (Michael Ramsey), proved to be a gifted child and student. He therefore naturally began studying mathematics, producing some results in graph theory, while also using his skills in mathematics and logic to get involved in issues and frameworks that Cambridge giants (especially George E. Moore, Russell, Wittgenstein, and Keynes) were developing. Ramsey worked on the extension and limits of logicism (foundations of mathematics, early steps of British analytical philosophy), thought about the validity of consequentialism (moral philosophy, philosophy of science), and helped identify bases for emerging economic interventionism (political economy). Each of Ramsey's forays was keen and successful enough to have sown durable seeds. Other great thinkers would, sometimes much later, go on to pick up on Ramsey's insights, integrating him into the chain of giants. From this common starting point, each biography then further explores Ramsey's contribution to the field the biographer is interested in, while adding any other meaningful intellectual relationships. ${ }^{4}$

Then came the book written by Ramsey's youngest sister, Margaret Paul, published posthumously in 2012. Paul's biography shifted the narrative by bringing a private point of view on Ramsey's life, sharing family stories and documents, abundant extracts of Frank and Lettice's diaries; brotherly as well as romantic correspondence. The story also included plenty of "secondary characters", who she brought to the fore: parents, uncles, friends, beloved women. Among them, Agnes and Arthur, Richard Braithwaite and Carl Ogden, Lionel Penrose and Maurice Dobb proved as vital as the giants in understanding Ramsey. Paul's account also offered some demystification. The genius was not born fully armed from the head of Zeus; he had not learned German in a week; he lived in an intellectual world, which was admittedly immensely powerful and revolutionary, but also very small. As Taylor stated in the afterword of the book, Paul had undertaken to record the life of her brother in her role as an academic.

\footnotetext{
${ }^{3}$ A first anthology was published by Richard Braithwaite after Ramsey's death in 1931. A second had already been published by Mellor, accompanied by active research on Ramsey's life and work (Mellor 1978, 1983).

${ }^{4}$ For the history of economics, it was necessary to add Arthur C. Pigou, Piero Sraffa and Roy Harrod to the list of the Cambridge giants (Gaspard 2003, Duarte 2009).
} 
Her biography was the result of many years of investigation and reconstruction, producing a periodization and thoughtful orchestration of Ramsey's life and works. ${ }^{5}$

Misak aggregates these narratives. She re-engages with the story of a giant among giants, while exploring all fields ${ }^{6}$ equally and investigating the players and events mentioned by Paul. The family, Winchester then Cambridge or Vienna, are presented here as a set of nonconcentric circles of social and scientific relationships. Disciplinary or transdisciplinary, public, private or secret circles, Misak decides to portray them all, the characters they include as well as their institutions, i.e., the rules that governed each of these interconnected societies. We know precisely when, and how long Ramsey attended each circle, and who he met there; we also know when and how parents, friends and colleagues were themselves involved in such circles. While Paul saw the family circle with her memories and Cambridge through Ramsey's eyes, Misak's large depth of field sheds some light on how the rules were taken hold by Ramsey and his relatives (Ramsey compared to his brother Michael, Ramsey compared to classmates, Ramsey among young scholars, Ramsey among Moore's students and Keynes's friends, Ramsey compared to Wittgenstein) and progressively manages to isolate from the context what made him unique. The systematical game of differentiation finally draws a Ramseyan way of appropriating and using the rules of the social game, and the rules of thought. Misak describes here a Ramsey who analyzes the meaning of the rules, grasps them in order to make better use of them, scrutinizes their consistency and inconsistency as a way to forge new paths. A thought process and character that enables him to survive in Winchester, to excel at the Cambridge clubs or at the Vienna Circle, to charm but also to shake "the giants" up. This ability is exercised from all angles with the sheer powers of a "thoroughbred", Misak tells us, borrowing here a metaphor from Schumpeter (p. xxiv). The intersection of experiences enables a gradual assertion of Ramsey's own path, which really took form upon the discovery of Charles S. Peirce's pragmatism, in the mid-1920s. But while some authors see such a discovery as a bifurcation in Ramsey's intellectual trajectory (Sahlin, 1990; Gaspard 2014), Misak sees it as a moment of channeling Ramsey's talents through the accomplishment of what he had always consciously or unconsciously sought: to develop a philosophy of action as much as a philosophy of mind, a philosophy likely to help human beings think better in order to live better, here and now. Misak makes pragmatism, as a philosophy using actions to judge the content of thought, resonate with the whole of Ramsey's life: his preoccupation for the human scale as expressed in his discussions on transcendence, his journey through socialist movements, his hesitations regarding his professional path (economics, politics, mathematics or philosophy?), and of course, his entire work.

The whole work is convincing and illuminating. For instance, in Ramsey's texts, and particularly in economics $(1926,1927,1928)$, there is tension between Ramsey's ability to formulate and represent the ideal - the axioms of rational choice through Dutch book mental experiments (1926); the rules that "God" would follow, like the revision of consistent systems of subjective beliefs with observations (1926), the intertemporal behavior a fair and imaginative nation would adopt (1928) - while making clear that ideal is out of reach for human fellows, who are certainly reasonable but also slightly shortsighted, highly socialized, and exceedingly

\footnotetext{
${ }^{5}$ See Duarte (2017) for an integration of this material in a history of economics perspective.

${ }^{6}$ The book notably devotes several chapters aiming to situate Ramsey's relationships with Cambridge economists. A highly interesting contribution of the book is also the account of Ramsey's journey through Socialist movements.
} 
mortal. Misak's contextualization enables a better understanding of the sources of such tension, that as economists we are inclined to think of in terms of norms (choices and temporal consistency) opposed to deviations to norms, or perhaps as normative versus descriptive analysis of behaviors. Misak's reconstruction highlights how, while Ramsey was writing his economics articles, he experienced the process of identifying the implications of pragmatism and most likely a kind of frustration with the economic conceptual tools he had at his disposal. She suggests interpreting the formulation of Ramsey's rule of saving as a way to convert formulations of the ideal into "tractable" propositions. Recalling that Ramsey was far from being a pure utilitarianist, she also suggests that we should not consider his contributions as guided by utility as an objective, rather as a proxy. After reading Misak, Ramsey's representations of rational behavior are shown to have been thought of as a (brilliant) support, rather than a norm.

When concluding this review, however, I am not entirely sure that it has not suffered from confirmation bias, and reading time has revealed some regrets and (open) questions. Misak's choices as a biographer are soberly mentioned in the preface and very quickly justified. We understand that she has set her sights on exhaustiveness and neutrality, that she will remain as close as possible to the archives and testimonies, that she has chosen to reveal everything, including the very private, and that she will offer very few of her own interpretations, except after having presented all the elements at her disposal on each subject. However, a more explicit reflection would have been welcome, for example on her choices relating to a possible hierarchy of sources, their compatibilities, and the status of the testimonies. Should we relate (believe) everything a rather young man writes in his diary? How do we combine archives and memories? In 2020, how do we use interviews conducted in the 1980s on events and relationships that took place in the 1920s? Can we relegate Paul's biography to the simple status of one testimony among others? And if so, why?

Secondary literature is used extensively in the book: previous biographies, historical studies on Cambridge or Vienna's figures and major institutions (Apostles Society, Bloomsbury, Mathematical Tripos, and so on), various articles about Ramsey's thought or posterity. This secondary literature is listed in an abundant bibliography, but is rarely referenced in the main text, except when exact quotations are used. We assume that Misak hunted down "facts" rather than interpretations in the literature. These facts, however, have been selected or established by others in different contexts, in inquiries and demonstrations that do not appear here. Misak sometimes settles debates, which are implicitly evoked, and therefore escape readers who are not already aware of it.

Finally, by wanting both to delve into the life of Frank Ramsey and provide an account of his genius - attested by the fact that his contributions not only had a lasting impression on his contemporaries, but also on the history of thought - Misak sometimes ends up juxtaposing almost dissonant points of view. For instance, on a few pages we encounter guest boxes from Partha Dasgupta, for whom Ramsey is emblematic of classical utilitarianism, and the contextualization of Misak, who reminds us that "Ramsey was not a full-out utilitarian, to whom discounting is the obvious and correct thing to do "(p. 318). Or Robin Boadway presenting "Ramsey's analysis" of optimal taxation requiring "a representative individual utility function" (p. 311) and Misak discussing, a few pages on, whether there are representative agents in Ramsey's economics. Throughout the book, Misak made the choice to portray Ramsey in his own words and in the words of others, and testimonies and archives align to weave a complete 
picture of Ramsey. As we read some of the invited contributions, however, testimonies (from the present) and Ramsey's portrayal no longer match. This divergence may bring into question the choice to recall, in some of the guest boxes, and discuss, at numerous points throughout the book, the late posterity of Ramsey's work, reminders that fall outside the scope of a biography stricto sensu. Between Dasgupta's and Boadway's viewpoints on Ramsey and Ramsey himself, there is all the distance between contemporary economics and Cambridge moral and political economy of the 1920s. There is also the history of economists reading Ramsey with their own theoretical questions, then transmitting a picture of Ramsey to their own readers. Misak's choice here may generate confusion for who choices to read a biography. The tension it creates however is admittedly a reminder that writing history of thought and biographies is necessary. And Misak's biography of Ramsey is a great one.

\section{References}

Bollobas, B., \& Thomason, A. 2003. Frank Ramsey. Combinatorics, Probability and Computing, 12(5-6), 469 - 475.

Dokic, J. and P. Engel. 2002. Frank Ramsey - truth and success. London: Routledge

Duarte, P. G. 2009. "Frank P. Ramsey: A Cambridge Economist." History of Political Economy 41 (3): $445-470$.

Duarte P. G. 2017. Frank P. Ramsey (1903-1930). In: Cord R. (eds) The Palgrave Companion to Cambridge Economics. Palgrave Macmillan, London.

Gaspard, M. 2003. "Ramsey's Theory of National Saving: A Mathematician in Cambridge". Journal of the History of Economic Thought 25 (4), 413-435.

Gaspard, M. 2014. "Logic, Rationality and Knowledge in Ramsey's Thought: Reassessing 'Human Logic.” Journal of Economic Methodology 21 (2): 139-157.

Mellor, D. H. 1978. Better Than the Stars. Broadcast on BBC Radio 3, 27 February 1978. Available at http://people.pwf.cam.ac.uk/dhm11/.

Mellor, D.H. 1983. The "Eponymous F. P. Ramsey", J. Graph Theory 7(1):9-13.

Mellor, D. H. 1995. “F. P. Ramsey”, Philosophy 70 (1995): 243 - 262.

Paul, M. 2012. Frank Ramsey (1903-1930): A Sister's Memoir. Huntingdon: Smith-Gordon.

Misak, C. 2016. Cambridge Pragmatism: From Peirce and James to Ramsey and Wittgenstein, Oxford University Press (2016)

Ramsey, F. P. 1926. “Truth and Probability”. In Philosophical Papers, edited by D. H. Mellor, Cambridge, UK: Cambridge University Press, 52-94

Ramsey, F. P. 1927. "A Contribution to the Theory of Taxation." Economic Journal 37 (145): 47-61.

Ramsey, F. P. 1928. “A Mathematical Theory of Saving.” Economic Journal 38 (152): 543559.

Ramsey, F. P. 1990. Philosophical Papers. Cambridge: Cambridge University Press. Edited by D. H. Mellor. 
Ramsey, F. P. 1991a. Notes on Philosophy, Probability and Mathematics. Naples, Italy: Bibliopolis, (Edizioni di Filosofia e Scienze). Edited by Maria C. Galavotti. Cambridge: Cambridge University Press.

Ramsey, F.P. 1991b. On Truth. Original Manuscript Materials (1927-1929) from the Ramsey Collection at the University of Pittsburgh. Ed. N. Rescher and U. Majer. Dordrecht: Kluwer.

Sahlin, Nils-Eric. 1990. The Philosophy of F. P. Ramsey. Cambridge: Cambridge University Press.

Taylor G. 2006. "Frank Ramsey. A Biographical Sketch". In: Galavotti M.C. (eds) Cambridge and Vienna. Vienna Circle Institute Yearbook. 